Pesq. Vet. Bras. 30(3):195-202, março 2010

\title{
Intoxicação experimental por Brachiaria decumbens em ovinos confinados ${ }^{1}$
}

\author{
Klaus C. Saturnino ${ }^{2}$, Thiago M. Mariani ${ }^{3}$, Marcos Barbosa-Ferreira ${ }^{4}$, Karine B. \\ Brum $^{5}$, Carlos Eurico dos Santos Fernandes ${ }^{5}$ e Ricardo A.A. Lemos ${ }^{6 *}$
}

\begin{abstract}
Saturnino K.C., Mariani T.M., Barbosa-Ferreira M., Brum K.B., Fernandes C.E.S. \& Lemos R.A.A. 2010. [Experimental poisoning by Brachiaria decumbens in feedlot sheep.] Intoxicação experimental por Brachiaria decumbens em ovinos confinados. Pesquisa Veterinária Brasileira 30(3):195-202. Departamento de Medicina Veterinária, Faculdade de Medicina Veterinária e Zootecnia, Universidade Federal de Mato Grosso do Sul, Campo Grande, MS 79070-900, Brazil. E-mail: rlemos@ nin.ufms.br

Brachiaria decumbens was fed as exclusive source of food to feedlot sheep. Sheep were evaluated in three periods of the year, of 60 days each, regarding their clinical status and was performed collection of blood samples to measure enzymatic activity of gamma glutamyltransferase and aspartate aminotransferase to evaluate their diagnostic importance and usefulness besides the clinical signs, necropsy and histopathology finds in hepatogenous photosensitization Brachiaria related. Out of 24 feedlot sheep, five died in the first period (February-April), four in the second (June-August) and two in the third (October-December). Main clinical signs were anorexia, jaundice, photophobia and two cases of slight dermatitis, besides dehydration, apathy and corneal opacity. Necropsy revealed generalized jaundice, distended gall bladder and liver with evident lobular pattern. The histological changes varied in severity according the time after the beginning of the plant ingestion; they were more significant in the liver and included bilestasis, swelling and vacuolation of hepatocytes, foammy macrophages, bile duct proliferation and mononuclear inflammatory cell infiltration, further crystal negative images were found within cytoplasm of macrophages present inside of hepatic sinusoid and in the periportal space and also optically active refringent crystal in the lumen of bile tubules. These finds are characteristic of hepatogenous photosensitization, mainly by presence of photophobia, even when the sheep did not present photodermatitis. The results of serum biochemistry activity, during the course of poisoning with strong relation between increased gamma glutamyltransferase activity, and lethality. Onset of arising gama glutamyltransferase activity was 11 days, in average, before beginning of clinical signs. Aspartate aminotransferase had increased activity only close to the beginning of clinical signs. Serum biochemistry results of GGT suggest that they are useful for a precocious diagnosis preventing deaths caused by ingestion of $B$. decumbens. Thirteen sheep didn't show clinical signs despite significant increases on serum enzyme activity, suggesting the existence of tolerant/resistant individuals. The experimental model of feedlot was adequate to study $B$. decumbens toxicosis in sheep.
\end{abstract}

INDEX TERMS: Brachiaria decumbens, photosensitization, sheep, pathology, feedlot.

\footnotetext{
${ }^{1}$ Recebido em 5 de junho de 2009.

Aceito para publicação em 23 de setembro de 2009.

Parte da Dissertação de Mestrado do primeiro autor.

2 Programa de Pós-Graduação em Ciência Animal, Departamento de Medicina Veterinária, Faculdade de Medicina Veterinária e Zootecnia (Famez), Universidade Federal de Mato Grosso do Sul (UFMS), Av. Filinto Müller s/n, Cidade Universitária, Campo Grande, MS 79070-900.

${ }^{3}$ Graduando em Medicina Veterinária, Centro Universitário da Grande Dourados (Unigran), Rua Balbina de Matos 2121, Dourados, MS 79824-900, Brasil.
}

\footnotetext{
${ }^{4}$ Programa de Mestrado em Produção e Gestão Agroindustrial, Uniderp-Anhanguera Agrárias, Rua Alexandre Herculano 1400, Bairro Jardim Veraneio, Campo Grande, MS 79037-280.

${ }^{5}$ Departamento de Patologia, Centro de Ciências Biológicas e da Saúde/UFMS, Cidade Universitária s/n, Cx. Postal 549, Campo Grande, MS 79070-900.

${ }^{6}$ Departamento de Medicina Veterinária, Faculdade de Medicina Veterinária e Zootecnia, Universidade Federal de Mato Grosso do Sul, Campo Grande, MS 79070-900, Brasil. *Autor para correspondência: rlemos@nin.ufms.br
} 
RESUMO.- Foi realizado estudo experimental de intoxicação por Brachiaria decumbens em ovinos confinados que receberam apenas esta forrageira como alimento. Os animais foram avaliados em três períodos do ano, com duração de 60 dias cada. As análises incluíram exame clínico e amostras de sangue para mensuração da atividade sérica das enzimas gama glutamiltransferase e aspartato aminotransferase com o objetivo de avaliar sua importância e utilidade no diagnóstico de fotossensibilização hepatógena causada pela planta. Foram descritos ainda, achados de necropsia e histopatológicos. Dos vinte e quatro animais confinados, cinco morreram no primeiro período (fevereiro a abril), quatro no segundo (junho a agosto) e dois no terceiro (outubro a dezembro), tendo como principais sinais clínicos anorexia, icterícia, fotofobia, dermatite leve, além de desidratação e apatia. Nos achados de necropsia foram constatados icterícia generalizada, vesícula biliar repleta e distendida, padrão lobular hepático evidente e, em dois casos, opacidade de córnea. As alterações microscópicas foram mais significativas no fígado com bilestase, tumefação e vacuolização de hepatócitos, sinusóides com macrófagos, proliferação de ductos e dúctulos biliares com infiltração linfocítica, que variaram na sua severidade conforme o tempo decorrido da ingestão da planta, além de imagens negativas de cristais no citoplasma de macrófagos presentes nos sinusóides hepáticos e no espaço periportal e cristais refringentes oticamente ativos, ocluindo a luz de ductos biliares. Os achados foram característicos de fotossensibilização hepatógena por $B$. decumbens, principalmente pela presença de fotofobia, mesmo quando os animais não apresentaram fotodermatite. $O$ aumento da atividade sérica da gama glutamiltransferase teve alta correlação com a morte dos animais. O surgimento da elevação da atividade sérica de gama glutamiltransferase foi, em média, 11 dias antes da constatação dos sinais clínicos, validando sua importância no diagnóstico e na prevenção. A aspartato aminotransferase teve resultados inconsistentes. Treze animais não apresentaram sinais clínicos, apesar de serem constatadas significativas elevações nos níveis séricos das enzimas em questão, sugerindo a existência de indivíduos tolerantes/resistentes dentro do intervalo estabelecido. O modelo experimental foi adequado na caracterização da intoxicação de ovinos por B. decumbens, oferecendo subsídios para estimar preventivamente o risco de morte de ovinos intoxicados pela planta, além de ser útil para a realização de novos estudos da intoxicação por $B$. decumbens.

TERMOS DE INDEXAÇÃO: Brachiaria decumbens, fotossensibilização, ovino, patologia, confinamento.

\section{INTRODUÇÃO}

Brachiaria decumbens é uma forrageira amplamente utilizada como fonte alimentar para ruminantes no Brasil devido sua boa adaptação e produção de massa em condições climáticas tropicais, entretanto tem sido associada à ocorrência de surtos de fotossensibilização nestes ani- mais (Abdullah et al. 1992, Driemeier et al. 2002). Os surtos de intoxicação de ovinos pastejando esta gramínea foram atribuídos, anteriormente, à micotoxina esporidesmina, produzida pelo fungo Pithomyces chartarum (Camargo et al. 1976). Atualmente acredita-se que saponinas esteroidais, presentes em $B$. decumbens, sejam responsáveis pelo aparecimento da fotossensibilização associada à ingestão da planta. Estas substâncias se acumulam na forma de sais insolúveis, sob forma de cristais de glicuronídeos de epismilagenina e episarsasapogenina nas células hepáticas e ductos biliares (Graydon et al. 1991, Miles et al. 1993, Miles et al. 1994). Haraguchi et al. (2003) sugerem que a saponina protodioscina seja a principal causa da fotossensibilização causada pela ingestão de $B$. decumbens.

A intoxicação por $B$. decumbens é descrita em bovinos (Nobre \& Andrade 1976, Opasina 1985, Abdullah et al. 1989, Rowe 1989, Lemos et al. 1996a, Lemos et al. 1996c, Lemos et al. 1997, Driemeier et al. 1998, Driemeier et al. 1999), ovinos (Graydon et al. 1991, Abdullah et al. 1992, Lajis et al. 1993, Lemos et al. 1996b, Abdullah \& Rajion 1997, Lemos et al. 2008, Cruz et al. 2000, Driemeier et al. 2002, Brum et al. 2007), caprinos (Opasina 1985, Lemos et al. 1998), bubalinos (Rozza et al. 2004, RietCorrea et al. 2007) e eqüinos (Barbosa et al. 2006).

Os animais jovens ou recém-desmamados apresentam maior susceptibilidade do que os adultos (Albernaz et al. 2008, Santos et al. 2008). Os ovinos são considerados mais susceptíveis que os bovinos à intoxicação e podem estar sujeitos ao problema em qualquer idade (Lemos et al. 1996b, Santos et al. 2008). Há relatos de que animais que tenham contato com $B$. decumbens pela primeira vez, sejam mais susceptíveis. Poucos estudos sugerem a existência de resistência por mecanismos de adaptação ou, talvez, por algum tipo de seleção natural (Riet-Correa et al. 2007).

A intoxicação por braquiárias causa quadro de fotossensibilização hepatógena caracterizada clinicamente por edema de face com formação de crostas ao redor dos olhos e orelhas (Abdullah et al. 1989, Graydon et al. 1991, Lemos et al. 1996b, Brum et al. 2007, Albernaz et al. 2008, Mendonça et al. 2008), icterícia (Abdullah \& Rajion 1997), opacidade de córnea (Brum e al. 2007, Opasina 1985) e secreção nasal além de ocular com aspecto seroso (Mendonça et al. 2008, Brum et al. 2007). São relatadas elevações nas atividades séricas das enzimas gama glutamiltransferase (GGT) (Brum et al. 2007, Albernaz et al. 2008, Mendonça et al. 2008, Santos Junior et al. 2008) e aspartato aminotransferase (AST) (Santos Junior et al. 2008), além dos níveis de bilirrubina (Brum et al. 2007, Albernaz et al. 2008, Mendonça et al. 2008, Santos Junior et al. 2008), mas em situações pontuais e sem sistematização de coleta de dados em surtos e experimentos.

Nos achados de necropsia são observados icterícia generalizada, fígado aumentado de volume com padrão lobular evidenciado e vesícula biliar repleta e distendida com bile espessada (Opasina 1985, Lemos et al.1996c). 
$\mathrm{Na}$ histopatologia encontram-se bilestase, tumefação e vacuolização de hepatócitos (Abdullah et al. 1989, Santos Junior et al. 2008), proliferação de ductos e canalículos biliares, sinusóides preenchidos por macrófagos, infiltrado linfocítico, além da presença de cristais birrefringentes em ductos biliares, dentro de hepatócitos e macrófagos (Cruz et al. 2000, Driemeier et al. 2002, Brum et al. 2007, Mendonça et al. 2008).

O presente trabalho teve por objetivo descrever o quadro clínico-patológico e a bioquímica sérica em ovinos confinados, alimentados somente por $B$. decumbens, durante diferentes épocas do ano, no município de Dourados, região sul de Mato Grosso do Sul.

\section{MATERIAL E MÉTODOS}

Foram utilizados vinte e quatro ovinos mestiços da raça Santa Inês, todos de pelagem escura, com média de três meses de idade, sendo doze machos e doze fêmeas, recém desmamados, pesando entre 22 e $25 \mathrm{~kg}$, oriundos de propriedade com experiência de dois anos de ovinocultura e que nunca utilizou Brachiartia decumbens como fonte alimentar. Os ovinos foram mantidos em baias teladas de $60 \mathrm{~m}^{2} \mathrm{com}$ piso de pedra britada fina. A baia possuía área ao ar livre e também cobertura consistindo de uma pequena casa com largura de $1,5 \times 2,0 \mathrm{~m}$ de comprimento, para proteção de eventuais chuvas e sol excessivo. Os animais permaneciam expostos ao sol durante o dia e eram recolhidos para a área coberta no período noturno. No início do experimento e 30 dias após, todos os animais foram everminados com cloridrato de levamisol ${ }^{7}$.

O estudo foi realizado em três períodos do ano com 60 dias de duração cada, com oito animais distintos em cada período, sendo quatro machos e quatro fêmeas. $\mathrm{O}$ primeiro período foi realizado entre os meses de fevereiro e abril; o segundo entre junho e agosto e o terceiro entre outubro e dezembro de 2008. Em todos os períodos experimentais os ovinos receberam água ad libitum e, como alimento volumoso, exclusivamente, $B$. decumbens cortada e fornecida fresca, colhida de canteiros com $140 \mathrm{~m}^{2}$, previamente cultivados. No primeiro e segundo períodos a planta estava verde, com sementes e medindo aproximadamente $55 \mathrm{~cm}$ de altura. No terceiro período, a planta estava verde, mas sem sementes. Durante todo o experimento, a forrageira foi cortada a uma altura aproximada de $10 \mathrm{~cm}$ do solo, pesada e fornecida aos ovinos imediatamente após o corte, em três administrações diárias às 7,13 e 17h. Foram utilizados cochos com $1,45 \mathrm{~m}$ de comprimento por $35 \mathrm{~cm}$ de largura e $18 \mathrm{~cm}$ de profundidade. $\mathrm{O}$ fornecimento da pastagem foi feito de forma que não houvesse sobras após o consumo, de modo que, diariamente, a quantidade de braquiária fornecida fosse sempre ajustada.

Amostras da pastagem foram colhidas semanalmente, totalizando oito coletas em cada período experimental para pesquisa de esporos de Pithomyces chartarum, de acordo com a técnica descrita por Di Menna \& Bailey (1973).

Foram colhidas amostras de sangue, por punção da veia jugular e colocadas em tubos de ensaio sem anticoagulante, envolvidos por papel laminado, mantidas em temperatura ambiente e encaminhadas para o Laboratório de Patologia Clínica Veterinária da Unigran, Centro Universitário da Grande Dourados, MS, para centrifugação e extração do soro. Análises bioquímicas de aspartato aminotransferase (AST) e gama glutamiltransferase (GGT) foram realizadas utilizando-se kits comerciais $^{8}$, sendo a leitura realizada com analisador bioquímico semi-automatizado 9 .

Diariamente os animais foram submetidos a exame clínico, observando-se a pele, se havia ou não áreas com lesões características da intoxicação, os olhos, em relação a lacrimejamento e edema de córnea, além das orelhas e toda área exposta ao sol. O comportamento também foi observado, caso os ovinos procurassem áreas sombreadas com o intuito de se protegerem do sol. Nos animais que morreram realizouse necropsia com colheita de fragmentos de diversos órgãos, que foram fixados em formol tamponado $10 \%$, processados rotineiramente para inclusão em parafina, cortados a cinco micrômetros e corados com hematoxilina-eosina.

A análise estatística foi feita pela comparação da atividade enzimática de GGT e AST, entre os períodos experimentais, de acordo com a sobrevivência ou não dos animais, pela análise de variância, modelo linear multivariado (teste de Duncan, para $\mathrm{P}<0,05)$ para efeitos principais e interativos. Para análise de correlação entre enzimas e entre estas com as mortes observadas em todos os períodos, os dados foram previamente classificados de acordo com a elevação ou não do perfil enzimático e a presença ou não de morte $(0$ e 1 , respectivamente). Esta análise foi feita pelo método bivariado, modelo não paramétrico de Spearman para $\mathrm{P}<0,05$.

\section{RESULTADOS}

O consumo médio diário estimado de Brachiaria decumbens por animal foi de $4,5 \mathrm{~kg}$ e produziu sinais clínicos da intoxicação e morte em 11 dos 24 ovinos, correspondendo a $45,8 \%$ de morbidade e $100 \%$ de letalidade. Os intervalos de dias entre o início da ingestão e surgimento dos sinais clínicos estão descritos no Quadro 1 , sendo que o menor intervalo encontrado foi de 20 dias e o maior de 62 dias. No primeiro e segundo períodos, ocorreram cinco e quatro mortes, respectivamente, quando havia sementes na pastagem, apesar da planta sempre encontrar-se verde. No terceiro período, ocorreram duas mortes, entretanto as pastagens não apresentavam sementes.

\section{Quadro 1. Número de dias entre início do experimento e surgimento dos sinais clínicos em ovinos que consumiram \\ Brachiaria decumbens em sistema de confinamento no Mato Grosso do Sul em 2008}

\begin{tabular}{ccc}
\hline Períodos & Primeiro animal & Último animal \\
\hline 1o período & 20 & 52 \\
2o período & 28 & 62 \\
3o período & 32 & 38
\end{tabular}

Dos 11 ovinos, 10 apresentaram fotofobia como principal sinal clínico e apenas dois apresentaram lesões de pele caracterizadas por edema da face e orelhas, seguido por formação de poucas crostas ao redor dos olhos.

Nos 11 ovinos necropsiados observaram-se diferentes graus de icterícia, sendo discreta (1 caso), moderada ( 5 casos) e acentuada (5 casos). Vesícula biliar distendida

\footnotetext{
${ }^{7}$ Levamisol Calbos ${ }^{\circledR}$ Injetável, Laboratórios Calbos, Curitiba, PR.

${ }^{8}$ Gold Analisa Diagnóstica Ltda, Belo Horizonte, MG.

${ }^{9}$ Modelo Bio- $200^{\circledR}$, Bioplus Produtos para Laboratórios Ltda, São Paulo, SP.
} 
pelo acúmulo de bile esteve presente em dez casos. Foi observado, em cinco casos, fígado difusamente amarelado, com aumento de volume, caracterizado por bordos arredondados e marca da impressão das costelas na superfície do órgão e padrão lobular evidenciado. Em dois casos havia áreas vermelhas enegrecidas, bilaterais, con-

Quadro 2. Principais sinais clínicos, achados de necropsia e histopatologia encontrados em ovinos confinados que morreram intoxicados por Brachiaria decumbens no Mato Grosso do Sul em 2008

\begin{tabular}{lccc}
\hline \multirow{2}{*}{ Sinais clínicos } & \multicolumn{3}{c}{ Períodos $^{\mathrm{a}}$} \\
\cline { 2 - 4 } & $1^{\circ}$ & $2^{\circ}$ & $3^{\circ}$ \\
\cline { 2 - 4 } & $\mathrm{n}=8$ & $\mathrm{n}=8$ & $\mathrm{n}=8$ \\
\hline Mortes & 5 & 4 & 2 \\
Anorexia & 5 & 4 & 2 \\
Apatia & 5 & 3 & 2 \\
Desidratação & 2 & 3 & 2 \\
Fotofobia & 5 & 3 & 2 \\
Inquietação & 5 & 1 & 0 \\
Lesão de pele & 1 & 0 & 1 \\
Prurido de face & 5 & 1 & 0 \\
Achados de necropsia & & & \\
Icterícia & 5 & 4 & 2 \\
Opacidade de córnea & 1 & 1 & 0 \\
Padrão lobular hepático evidente & 4 & 0 & 1 \\
Vesícula biliar repleta e distendida & 5 & 4 & 1 \\
Histopatologia & & & \\
$\quad$ Bilestase & & 3 & 2 \\
Infiltrado linfocítico & 5 & 3 & 1 \\
Proliferação de ductos e canalículos biliares & 5 & 2 & 1 \\
Sinusóides preenchidos por macrófagos & 5 & 4 & 2 \\
Tumefação e vacuolização de hepatócitos & 5 & 4 & 2 \\
& & 5 &
\end{tabular}

solidadas, na região antero-ventral do pulmões, que estavam aderidas às costelas.

As principais alterações histológicas foram observadas no fígado de 11 ovinos. Havia desorganização do padrão estrutural do órgão, com infiltração de macrófagos. Os macrófagos apresentavam citoplasma abundante e vesiculoso com núcleos deslocados para a periferia. Além disso, havia retenção biliar no citoplasma e nos espaços extracelular, associadas à tumefação e vacuolização difusa dos hepatócitos. Necrose individual disseminada destas células também foi encontrada. Foram observadas, em três ovinos, imagens negativas de cristais no citoplasma de macrófagos presentes nos sinusóides hepáticos e no espaço periportal. Cristais refringentes oticamente ativos, ocluindo a luz de ductos biliares foram observados em um ovino.

Múltiplos focos de infiltrado linfocítico foram observados em nove ovinos, em dois dos quais também havia infiltrado de neutrófilos. Em dois ovinos, havia a formação de células multinucleadas, resultantes da fusão de macrófagos. Nestes dois animais, havia produção insipiente de tecido conjuntivo que se iniciava na região periportal e invadia o parênquima hepático. Discreta proliferação de células de ductos e dúctulos biliares, associada à infiltração de células mononucleares foram observadas em 10 casos. Dois ovinos apresentaram pleuro-pneumonia fibrino-necrosante que se caracterizava por áreas extensas de necrose alveolar, com acentuado infiltrado de neutrófilos ocluindo a luz dos alvéolos, brônquios e bronquíolos. Os septos interlobulares estavam distendidos por intensa deposição de fibrina, infiltrado de neu-

Quadro 3. Comparação de médias das variáveis bioquímicas entre animais mortos e sobreviventes, em cada período experimental em ovinos que consumiram Brachiaria decumbens em sistema de confinamento no Mato Grosso do Sul em 2008

\begin{tabular}{|c|c|c|c|c|c|c|}
\hline \multirow[t]{2}{*}{ Variável } & \multicolumn{2}{|c|}{ 1ำ Período } & \multicolumn{2}{|c|}{ 2 Período } & \multicolumn{2}{|c|}{ 3o Período } \\
\hline & Mortos $\mathrm{n}=5$ & Sobreviventes $n=3$ & Mortos $n=4$ & Sobreviventes $n=4$ & Mortos $\mathrm{n}=2$ & Sobreviventes $n=6$ \\
\hline $\begin{array}{l}\text { GGT } \\
\text { AST }\end{array}$ & $\begin{array}{c}83,8 \pm 12,5^{\mathrm{A}} \\
95,4 \pm 7,5^{\mathrm{A}}\end{array}$ & $\begin{array}{c}55,3 \pm 11,0^{\mathrm{B}} \\
65,4 \pm 6,6^{\mathrm{A}}\end{array}$ & $\begin{array}{c}90,5 \pm 10,3^{\mathrm{A}} \\
86,6 \pm 6,1^{\mathrm{A}}\end{array}$ & $\begin{array}{c}62,0 \pm 10,3^{\mathrm{B}} \\
56,6 \pm 6,1^{\mathrm{A}}\end{array}$ & $\begin{array}{c}69,1 \pm 10,0^{A^{*}} \\
103,8 \pm 6,0^{A}\end{array}$ & $\begin{array}{c}40,6 \pm 12,8^{\mathrm{B}} \\
73,7 \pm 7,7^{\mathrm{B}}\end{array}$ \\
\hline
\end{tabular}

GGT = gama glutamiltransferase, $\mathrm{AST}=$ aspartato aminotransferase.

${ }^{*} \mathrm{P}<0,05$ entre períodos experimentais; $A B=P<0,05$ entre a sobrevivência dentro do período.

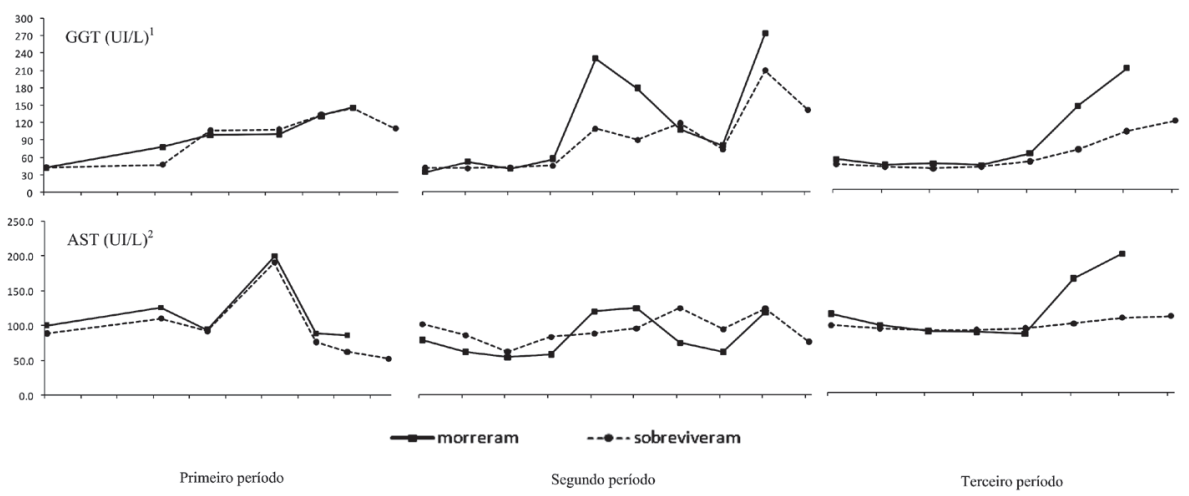

Fig.1. Comparação da média dos valores de GGT e AST entre ovinos confinados que morreram ou sobreviveram após ingestão de Brachiaria decumbens de acordo com a época do ano no Mato Grosso do Sul em 2008. ${ }^{1} \mathrm{P}<0,05$ no segundo e terceiro período; ${ }^{2} \mathrm{P}<0,05$ no terceiro período. 
trófilos e formação de trombos. O Quadro 2 sumariza os principais achados clínicos, necroscópicos e histológicos.

As atividades séricas das enzimas GGT e AST foram analisadas utilizando-se as médias dos três períodos, associando-as à sobrevivência ou morte dos ovinos dentro de seu respectivo grupo (Quadro 3). A atividade da enzima AST, somente apresentou diferença significativa $(P<0,05)$ entre os ovinos que sobreviveram e os que morreram no terceiro período, ao passo que a atividade da GGT apresentou diferença estatística significativa $(P<0,05)$ entre e dentro de cada período experimental. As freqüências das atividades das enzimas, entre os grupos de animais que sobreviveram e os que morreram em cada período, foram semelhantes no primeiro período, mas variáveis no segundo e terceiro períodos, com tendência a elevação antes da

Quadro 4. Correlação (Spearman) entre variáveis bioquímicas e morte em ovinos que consumiram Brachiaria decumbens em sistema de confinamento no Mato Grosso do Sul em 2008

\begin{tabular}{ccc}
\hline Enzimas & Morte & AST \\
\hline GGT & $0,48^{*}$ & $n s$ \\
AST & ns & -
\end{tabular}

GGT = gama glutamiltransferase, AST = aspartato aminotransferase.

${ }^{*} \mathrm{P}<0,05$; ns: não significativo.

Quadro 5. Aparecimento da elevação da atividade bioquímica sérica e de sinais clínicos após o início do consumo de Brachiaria decumbens em sistema de confinamento no Mato Grosso do Sul em 2008

\begin{tabular}{ccccc}
\hline \multirow{2}{*}{ Período } & Animal & \multicolumn{3}{c}{ Intervalo de dias } \\
\cline { 2 - 5 } & & GGT & AST & Sinais clínicos ** \\
\hline & 1 & $33(10)$ & $47(-4)^{*}$ & 43 \\
1 & 2 & $23(29)$ & $47(5)$ & 52 \\
$(01 / 02-08 / 04)$ & 3 & $23(-3)$ & $x$ & 20 \\
& 4 & $33(15)$ & $47(1)$ & 48 \\
& 7 & $23(-2)$ & $23(-2)$ & 21 \\
2 & 9 & $21(7)$ & $28(0)$ & 28 \\
$(10 / 06-12 / 08)$ & 10 & $14(16)$ & $35(-5)$ & 30 \\
3 & 11 & $28(0)$ & $28(0)$ & 28 \\
$(28 / 10-16 / 12)$ & 14 & $28(34)$ & $56(6)$ & 62 \\
& 19 & $29(3)$ & $36(-4)$ & 32 \\
& $29(9)$ & $43(-5)$ & 38
\end{tabular}

( ) Intervalo de dias para o aparecimento de sinais clínicos após a elevação dos valores da bioquímica sanguínea.

* Valor negativo: os sinais clínicos apareceram antes da elevação dos valores da bioquímica sanguínea.

**Dias após o início do consumo de $B$. decumbens.

X Animal já apresentava valores elevados de AST, não sendo possível realizar sua avaliação quanto a esta enzima.

morte (Fig.1); entretanto, observou-se elevação e queda abrupta da atividade destas enzimas também entre os ovinos que sobreviveram.

Das enzimas estudadas, a elevação da atividade de AST não apresentou correlação significativa com a morte dos animais, ao contrário da GGT $(r=0,48 ; P<0,05)$ conforme mostrado no Quadro 4. O tempo de aparecimento dos sinais clínicos teve grande variação, desde antes do início da elevação da atividade de GGT, em três ovinos, ou até 34 dias após (Quadro 5); todavia, a ocorrência do início de sintomatologia prevaleceu após a elevação da atividade desta enzima.

Em todas as amostras de forragem colhidas para contagem de esporos de $P$. chartarum, os resultados foram inferiores a 5.000 esporos por grama de pastagem verde.

\section{DISCUSSÃO}

A maior parte das informações sobre intoxicação por braquiárias são referentes a criações extensivas em sistema de pastoreio (Brum et al. 2007, Mendonça et al. 2008). Os modelos descritos para reprodução experimental da doença utilizam como metodologia a introdução dos animais em pastagens de Brachiaria decumbens sob condições controladas (Cruz et al. 2000, Driemeier et al. 2002, Albernaz et al. 2008, Santos Junior et al. 2008) ou com administração de extratos fracionados da planta (Cruz et al. 2000). O presente trabalho foi realizado no sistema de confinamento o qual possibilitou controlar variáveis que ocorrem em situações de campo, demonstrando ser eficiente para a reprodução experimental da intoxicação.

A planta foi tóxica para os ovinos nas quantidades consumidas. $\mathrm{O}$ aparecimento dos sinais clínicos iniciou, em média, nos primeiros 36 dias de ingestão da pastagem. Na literatura consultada, há variação no início do aparecimento dos sinais clínicos após o início do consumo da pastagem pelos ovinos. Assim, são descritos sinais clínicos após 7 dias (Santos Junior et al. 2008), 14 dias (Albernaz et al. 2008) e 21 dias (Graydon et al. 1991). A variação no tempo para o aparecimento dos sinais clínicos pode estar relacionada a diferentes variáveis, desde a quantidade de saponinas na pastagem que pode variar conforme a época do ano, estado fisiológico e o manejo da forrageira (Santos Junior et al. 2008), além da susceptibilidade e adaptação dos ovinos.

No presente estudo o primeiro e o segundo períodos demonstraram ser mais eficazes na reprodução da intoxicação no modelo experimental apresentado, uma vez que mais ovinos foram acometidos nestes dois primeiros espaços de tempo. Além disso, a coincidência de haver sementes na pastagem pode sugerir que exista alguma relação entre o nível de toxicidade e o período fisiológico (vegetação e/ou reprodução) da planta. Apesar de esta observação corroborar os achados de Brum et al. (2009) em que foram observados aumentos da concentração de protodioscina justamente na fase de queda das sementes, outros autores (Riet Correa \& Méndez 2007) relataram que a intoxicação pode ocorrer em qualquer época do ano, mas principalmente durante a estação chuvosa. Portanto, ainda há carência de informações mais apuradas para se chegar a uma conclusão sobre qual o fator preponderante para que $B$. decumbens se apresente mais tóxica.

Além disso, em relação à suscetibilidade animal, não se dispõe de dados sobre rebanhos controlados, onde se 
saberia quais genealogias seriam resistentes/tolerantes à intoxicação por $B$. decumbens. Assim, deve-se levar em conta que os ovinos que morreram intoxicados nos primeiros dois períodos poderiam ser mais sensíveis que aqueles que compunham o grupo do último período. Portanto estudos aprofundados com o intuito de se avaliar rebanhos suscetíveis e resistentes estão sendo desenvolvidos pelo presente grupo de pesquisa para se conhecer melhor sobre este assunto.

Os sinais clínicos observados nos ovinos confinados foram similares aos previamente descritos na intoxicação por B. decumbens (Graydon et al. 1991, Brum et al. 2007, Albernaz et al. 2008, Mendonça et al. 2008, Santos Junior et al. 2008). A maioria dos ovinos do presente experimento não apresentou lesões de pele características de fotossensibilização. Isto se deve, provavelmente, ao fato dos ovinos deste experimento serem de pelagem escura. Santos Junior et al. (2008) também observaram baixa freqüência de lesões de pele, onde, de um total de 12 animais intoxicados, apenas um apresentou erosão e ulceração, o único que possuía pelagem clara. Graydon et al. (1991) relataram que ovinos de pelagem escura, em um mesmo experimento onde animais de pele clara tiveram lesões evidentes, não apresentaram sinais clínicos de intoxicação. Portanto, pode-se sugerir que a pigmentação da pele é um aspecto importante do ponto de visto clínico devido à menor predisposição ao aparecimento de lesões da fotossensibilização de origem hepática causada por B. decumbens.

No presente trabalho o fígado foi o órgão mais acometido, e isto foi comprovado pelos achados de necropsia e histopatológicos, principalmente pela observação macroscópica de icterícia generalizada, além de presença de tumefação de hepatócitos e bilestase. Estas observações também foram relatadas por outros autores (Brum et al. 2007, Albernaz et al. 2008, Mendonça et al. 2008, Santos Junior et al. 2008).

Os resultados referentes à AST e GGT, demonstraram que há aumento significativo da atividade destas enzimas nos ovinos que apresentaram sinais de intoxicação, quando comparados com os ovinos que não adoeceram, apesar de existirem casos de elevação sem surgimento dos sinais clínicos. Estas diferenças observadas poderiam estar relacionadas com a capacidade de detoxificação individual das saponinas ou devido à resistência individual de cada animal (Castro et al. 2007). Os ovinos que, apesar das elevações enzimáticas, não adoeceram, possivelmente eram mais resistentes à intoxicação por $B$. decumbens, pois sofreram a ação hepatotóxica da forragem, mas conseguiram superar os efeitos prejudiciais da toxina, corroborando as observações de Santos Junior et al. (2008).

A elevação das atividades de GGT é descrita nas intoxicações tanto em casos espontâneos (Brum et al. 2007, Mendonça et al. 2008) como na reprodução experimental (Albernaz et al. 2008, Santo Junior et al. 2008) da intoxicação por Brachiaria spp. O aumento da atividade da GGT está fortemente relacionado à ocorrência de bilestase, pois é uma enzima de indução, ou seja, está presente nas membranas celulares e o aumento de sua produção pode ser tanto devido a um estímulo que resulta em sua maior liberação pelas células, quanto pela liberação de fragmentos de membranas que contêm esta enzima (Thrall et al. 2006). Isto explicaria a elevação da atividade da GGT sérica que, devido à ação detergente dos ácidos biliares na bilestase resultaria na solubilização da enzima aderida à membrana celular liberando-a, desta forma, na corrente sangüínea. Além disso, ruminantes apresentam estreita amplitude sérica de GGT, tornado-a mais sensível e específica no diagnóstico de bilestase (Stockham \& Scott 2008).

Apesar da variação individual da atividade enzimática de GGT, com exceção de três casos, os sinais clínicos apareceram depois da elevação da atividade dessa enzima, sugerindo que este teste de função hepática pode ser empregado na identificação prévia do risco da ocorrência da sintomatologia da intoxicação em rebanhos de ovinos. Os resultados obtidos também revelaram que a elevação sérica da atividade de GGT é indicativa do aumento do risco de morte na intoxicação experimental por B. decumbens em ovinos.

Dessa forma, estes achados permitem inferir que esse exame, se realizado em amostra significativa do rebanho, seria útil para a triagem, reduzindo perdas econômicas, ao permitir a retirada dos ovinos da pastagem antes do aparecimento dos sinais clínicos. Entretanto estas observações não têm valor diagnóstico quando os casos são analisados individualmente, conforme observado no presente estudo e por Santos Junior et al. (2008).

A elevação da atividade sérica da enzima AST caracteriza lesão de hepatócitos visto que, em ruminantes, esta enzima está presente em grande quantidade nestas células (Thrall et al. 2006). Como esta elevação ocorreu, no rebanho, próximo ao aparecimento dos sinais clínicos, a atividade de AST não se presta da mesma forma que a GGT para a triagem da fotossensibilização hepatógena, quando os ovinos poderiam ser retirados da pastagem antes da apresentação dos sinais clínicos da intoxicação.

Entretanto, outros autores (Santos Junior et al. 2008) descrevem que mesmo aumentos consideráveis de AST e GGT não puderam ser correlacionados com o diagnóstico e prognóstico da intoxicação, uma vez que ovinos sem sinais clínicos apresentaram elevações superiores nos níveis da atividade destas enzimas.

No presente trabalho, apesar de haver ovinos que apresentaram atividade enzimática de AST e GGT elevadas e não tiveram nenhum sinal clínico, a retirada dos animais da pastagem quando os níveis de GGT forem altos ainda é justificada para diminuir perdas no rebanho.

Os achados de necropsia foram semelhantes em todos os ovinos e estão de acordo com relatos de intoxicação espontânea e experimental (Brum et al. 2007, Albernaz et al. 2008, Mendonça et al. 2008). Salienta-se a ocorrência de icterícia acentuada na maioria dos ovi- 
nos necropsiados no presente estudo, enquanto outros autores descrevem a sua ausência ou de intensidade leve a moderada (Brum et al. 2007, Santos Junior et al. 2008).

Os achados histológicos observados neste experimento são semelhantes à intoxicação espontânea ou experimental em ovinos. Estas descrições também mencionam bilestase (Mendonça et al. 2008), infiltrado linfocítico (Graydon et al. 1991, Cruz et al. 2000, Brum et al. 2007, Albernaz et al. 2008, Mendonça et al. 2008, Santos Junior et al. 2008), proliferação de ductos e dúctulos biliares (Cruz et al. 2000, Brum et al. 2007, Mendonça et al. 2008), sinusóides preenchidos por macrófagos (Driemeier et al. 2002, Brum et al. 2007, Albernaz et al. 2008, Santos Junior et al. 2008) além de tumefação e vacuolização de hepatócitos (Brum et al. 2007, Albernaz et al. 2008, Santos Junior et al. 2008), cristais birrefringentes em ductos biliares, dentro de hepatócitos e macrófagos (Cruz et al. 2000, Mendonça et al. 2008), que foram também observados nos ovinos do presente trabalho.

\section{CONCLUSÕES}

O modelo de confinamento de ovinos, tendo como fonte alimentar apenas $B$. decumbens, demonstrou ser eficaz na reprodução experimental de intoxicação pela forrageira.

A GGT é uma enzima que pode ser utilizada como prova bioquímica sérica na prevenção de mortes de ovinos que ingerem a planta.

Há diferenças individuais entre ovinos na suscetibilidade e resistência à intoxicação por $B$. decumbens.

A pastagem se revelou mais tóxica durante o período reprodutivo, ou seja, durante a produção de sementes.

Agradecimentos.- À Escola de Qualificação Rural (EQUALI) pelo apoio técnico e ao CNPQ pelo apoio financeiro através do Projeto Milenium, registrado no CNPq, sob processo no.420012/2005-2.

\section{REFERÊNCIAS}

Abdullah A.S., Noordin M.M. \& Rajion M.A. 1989. Neurological disorders in sheep during signal grass (Brachiaria decumbens) toxity. Vet. Hum. Toxicol. 31(2):128-29.

Abdullah A.S., Lajis N.H., Davies J.B.B., Rajion M.A. \& Mustapha W. 1992. Hepatotoxic constituents in the rumen of Brachiaria decumbens intoxicated sheep. Vet. Hum. Toxicol. 34(2):154-155.

Abdullah A.S. \& Rajion M.A. 1997. Dietary factors affecting entero-hepatic function of ruminants in the tropics. Anim. Feed. Sci. Technol. 69:8386.

Albernaz T.T., Silveira J.A.S., Reis A.S.B., Oliveira C.H.S., Oliveira C.M.C., Duarte M.D., Cerqueira V.D., Riet-Correa G. \& Barbosa J.D. 2008. Fotossensibilização em ovinos associada à ingestão de Brachiaria brizantha no Pará. Anais Endivet, Campo Grande, MS, p.73-74.

Barbosa J.D., Oliveira C.M.C., Tokarnia C.H. \& Peixoto P.V. 2006. Fotossensibilização hepatógena em eqüinos pela ingestão de Brachiaria humidicola (Graminae) no Estado do Pará. Pesq. Vet. Bras. 26(3):147-153

Brum K.B., Haraguchi M., Garutti M.B., Nóbrega F.N., Rosa B., Fioravanti M.C.S. 2009. Steroidal saponin concentrations in Brachiaria decumbens and $B$. brizantha at different developmental stages. Ciência Rural 39(1):279-281.
Brum K.B., Haraguchi M., Lemos R.A.A., Riet-Correa F. \& Fioravanti M.C.S. 2007. Crystal-associated cholangiopathy in sheep grazing Brachiaria decumbens containing the saponin protodioscin. Pesq. Vet. Bras. 27(1):39-42.

Camargo W.V.A., Nazario W. \& Fernández N.S. 1976. Fotossensibilização em bovinos de corte. Biológico, São Paulo, 42(5):249-261.

Castro M.B., Moscardini A.R.C., Reckziegel G.C., Novaes E.P.F., Mustafa V.S., Paludo G.R., Borges J.R.J. \& Riet-Correa F. 2007. Susceptibilidade de ovinos a intoxicação por Brachiaria decumbens. Anais V Congresso Latinoamericano de Especialistas em Pequeños Rumiantes y Camélidos Sudamericanos, Mendoza, Argentina, p.5759.

Cruz C., Driemeier D., Pires V.S., Colodel E.M., Taketa A.T.C. \& Schenkel E.P. 2000. Isolation of steroidal sapogenins implicated in experimentally induced cholangiopathy of sheep grazing Brachiaria decumbens in Brazil. Vet. Hum. Toxicol. 42(3):142-45.

Di Menna M.E. \& Bailey J.R. 1973. Pithomyces chartarum spore counts in pasture. N. Z. J. Agric. Res. 16:343-51.

Driemeier D., Barros S.S., Peixoto P.V., Tokarnia C.H., Döbereiner J. \& Brito M.F. 1998. Estudos histológico, histoquímico e ultra-estrutural de fígados e linfonodos de bovinos com presença de macrófagos espumosos ("foam cells"). Pesq. Vet. Bras. 18(1):29-34.

Driemeier D., Döbereiner J., Peixoto P.V. \& Brito M.F. 1999. Relação entre macrófagos espumosos ("foam cells") no fígado de bovinos e ingestão de Brachiaria spp no Brasil. Pesq. Vet. Bras. 19(2):79-83.

Driemeier D., Colodel E.M., Seitz A.L., Barros S.S. \& Cruz C.E.F. 2002. Study of experimentally induced lesions in sheep by grazing Brachiaria decumbens. Toxicon 40:1027-1031.

Graydon R.J., Hamid H., Zahari P. \& Gardiner C. 1991. Photosensitization and crystal-associated colangiohepatopathy in sheep grazing Brachiaria decumbens. Aust. Vet. J. 68:234-236.

Haraguchi M., Cunha H.A., Mimaki Y., Brum K.B., Lemos R.A.A., Yokosuka A. \& Sashida Y. 2003. Furostanol glicosídicos nas folhas de Brachiaria decumbens. Anais 26 $6^{\mathrm{a}}$ Reun. Anu. Soc. Bras. Química, Poços de Caldas, MG, p.66. (Resumo)

Lajis N.H., Abdullah S.A., Salim J.S., Bremmer J.B. \& Khan M.N. 1993. Epi-sarsasapogenin and epi-smilagenin isolated from the rumen content of sheep intoxicated by Brachiaria decumbens. Steroids 58:387-389.

Lemos R.A.A., Osório A.L.A.R., Rangel J.M.R. \& Herrero Junior G.O. 1996a. Fotossensibilização e colangiopatia associada a cristais em bezerros ingerindo Brachiaria brizantha. Arqs Inst. Biológico, São Paulo, 63(Supl.):22.

Lemos R.A.A., Ferreira L.C.L., Silva S.M., Nakazato L. \& Salvador S.C. 1996b. Fotossensibilização e colangiopatia associada a cristais em ovinos em pastagem com Brachiaria decumbens. Ciência Rural 26(1):109-113.

Lemos R.A.A., Oliveira V.A., Herrero Junior G.O., Ferreira M.B. \& Almeida A.J. 1996c. Fotossensibilização e colangiopatia associada a cristais em bovinos lactentes associada à ingestão de Brachiaria decumbens. XV Panvet, Campo Grande, p.170. (Resumo)

Lemos R.A.A., Salvador S.C. \& Nakazato L. 1997. Photosensitization and crystal-associated cholangiohepatopathy in cattle grazing Brachiaria decumbens in Brazil. Vet. Hum. Toxicol. 39(6):376-377.

Lemos R.A.A., Nakazato L., Herrero Junior G.O., Silveira A.C. \& Porfírio L.C. 1998. Fotossensibilização e colangiopatia associada a cristais em caprinos mantidos sob pastagens de Brachiaria decumbens no Mato Grosso do Sul. Ciência Rural 28(3):507-510.

Lemos R.A.A. \& Leal C.R.B. 2008. Doenças de impacto econômico em bovinos de corte: perguntas e respostas. UFMS, Campo Grande, p.232-36

Mendonça F.S., Camargo L.M., Freitas S.H., Dória R.G.S., BaratellaEvêncio L. \& Neto J.E. 2008. Aspectos clínicos e patológicos de um surto de fotossensibilização hepatógena em ovinos pela ingestão de 
Brachiaria decumbens (Gramineae) no município de Cuiabá, Mato Grosso. Ciênc. Anim. Bras. 9(4):1034-1041.

Miles C.O., Wilkins A.L., Munday S.C., Flayoen A., Holland P.T. \& Smith B.L. 1993. Identification of insoluble salts of the $\beta$-D-glucuronides of episarsasapogenin and epismilagenin in the bile of lambs with alved and examination of Narthecium ossifragum, Tribulus terrestris and Panicum miliaceum for sapogenins. J. Agric. Food Chem. 41(6):914917.

Miles C.O., Wilkins A.L., Erasmus G.L. \& Kellerman T.S. 1994. Photosensivity in South Africa. VIII Ovine metabolism of Tribulus terrestris saponins during experimentally induced geeldikkop. Onderstepoort J. Vet. Res. 61(4):351-359.

Nobre D. \& Andrade S.O. 1976. Relação entre fotossensibilização em bovinos jovens e a gramínea Brachiaria decumbens Stapf. Biológico, São Paulo, 42:249-258.

Opasina B.A. 1985. Photosensitization jaundice syndrome in west African dwarf sheep and goats grazed on Brachiaria decumbens. Tropical Grasslands 19(3):120-123.

Riet-Correa F. \& Méndez M.C. 2007. Intoxicações por Plantas e Micotoxinas, p.99-221. In: Riet-Correa F., Schild A.L., Lemos R.A.A. \&
Borges J.R.J. (Eds), Doenças de Ruminantes e Eqüídeos. Vol.2, Palloti, Santa Maria.

Rozza D.B., Seitz A.L., Santos E.O. \& Driemeier D. 2004. Fotossensibilização por Brachiaria decumbens em búfalo. Pesq. Vet. Bras. 24(Supl):55-56.

Rowe L.D. 1989. Photosensitization problems in livestock. Vet. Clin. North Am., Food Anim. Pract. 5(2):301-319.

Santos J.C.A., Riet-Correa F., Simões S.V.D. \& Barros C.S.L. 2008. Patogênese, sinais clínicos e patologia das doenças causadas por plantas hepatotóxicas em ruminantes e eqüinos no Brasil. Pesq. Vet. Bras. 28(1):1-14.

Santos Junior H.L., Moscarini A.R.C., Paludo G., Riet-Correa F., Borges J.R.J \& Castro M.B. 2008. Toxicidade de diferentes estágios de crescimento da Brachiaria decumbens a ovinos. Anais Endivet, Campo Grande, MS, p.135-136.

Stockham S.L., Scott M.A. 2008. Fundamentals of Veterinary Clininical Pathology. $2^{\text {nd }}$ ed. Blackwell Publishing, lowa, p.639-674.

Thrall M.A., Baker D.C., Campbell T.W., DeNicola D., Fettman M.J., Lassen E.D., Rebar A. \& Weiser G. 2006. Hematologia e Bioquímica Clínica Veterinária, Roca, São Paulo, p.335-354. 